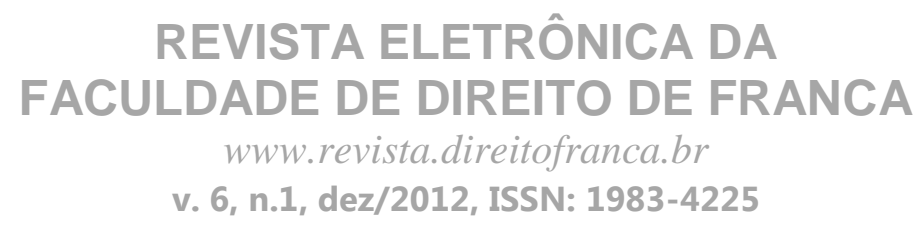

\title{
LEGITIMIDADE E DEMOCRATIZAÇÃO NOS PROCESSOS DE CONTROLE DE CONSTITUCIONALIDADE E O DIREITO COMO INTEGRIDADE NAS DECISÕES SOBRE A PARTICIPAÇÃO DO AMICUS CURIAE JUNTO AO SUPREMO TRIBUNAL FEDERAL
}

Ludmila Lais Costa Lacerda

http://buscatextual.cnpq.br/buscatextual/visualizacv.do?id=K4321120Y6

\begin{abstract}
Resumo: O presente artigo encontra-se no contexto do direito constitucional e tem como objeto central o instituto do amicus curiae, sendo que este possibilita a participação da sociedade durante os trâmites judiciais (constitucionais). Busca-se suscitar a reflexão e o debate, sobre a forma de admissão para a atuação da figura do amicus curiae perante o Supremo Tribunal Federal, fazer-se uma oportunidade ampla, legítima e democrática de participação cidadã, diante do complexo sistema social brasileiro. O tema é relevante devido atribuição à figura amicus curiae de agente possibilitador da abertura da jurisdição constitucional, permitindo contribuição argumentativa para desenvolvimento das decisões judiciais, reafirmação dos compromissos do Supremo Tribunal Federal com a Constituição da República Federativa do Brasil de 1988 e de sua responsabilidade contramajoritária, bem como, exercício de integração no Estado Constitucional brasileiro. O instituto do amicus curiae significa possibilidade de comunicação entre a sociedade civil e o judiciário. Através dessa participação, os cidadãos podem levar contribuição ao processo de tomada de decisão da Corte Suprema, almeja-se, assim, a qualidade da prestação jurisdicional e legitimação aos julgamentos do Supremo Tribunal Federal no contexto de sua função precípua de guardião da Constituição.
\end{abstract}

Palavras-chaves: Amicus Curiae - Corte Constitucional - Supremo Tribunal Federal Intérpretes Constitucionais

Legitimacy and Democratization in the Process of Constitutionality Control and the Law as a Integrity in the Decisions about the Participation of Amicus Curiae in the Supreme Federal Court

Abstract: The present article is in the context of constitutional law and has as its main object the amicus curiae institute which enables participation of society during the court proceedings (constitutional). It seeks to evoke reflection and debate on the form of admission of the amicus curiae before the Supreme Court, make a broad, legitimate and democratic opportunity to participation of citizens considering the complex Brazilian social system. The theme is relevant due to the allocation of the amicus curiae as an agent who enables opening of the constitutional jurisdiction, allowing argumentative contribution to development of judicial decisions, reaffirming the commitments of the Supreme Court with the Federal Constitution and its countermajoritarian responsibility, as well as the integration in the Constitutional Brazilian State. The amicus curiae institute implies the possibility of communication between civil society and the Judiciary. Through this participation, citizens may bring contribution to the decision-making process of the Supreme Court. Thus, it is sought to achieve quality of adjudication and judgments 


\section{REVISTA ELETRÔNICA DA \\ FACULDADE DE DIREITO DE FRANCA \\ www.revista.direitofranca.br \\ v. 6, n.1, dez/2012, ISSN: 1983-4225}

legitimation of the Supreme Court in the context of their major role as guardian of the Constitution.

Keywords: amicus curiae, constitutional court, Supreme Federal Court, Constitutional interpreters

\section{INTRODUÇÃO}

O termo amicus curiae tem origem latina, e sua tradução corresponde ao termo 'amigo da corte'. Foi instituído pelas leis romanas, e plenamente desenvolvido na Inglaterra pela English Common Law, sendo aplicado com grande ênfase nos Estados Unidos (BUENO FILHO, 2002).

Conforme a Constituição da República Federativa do Brasil de 1988 (CF/88) as normas infraconstitucionais devem respeitar requisitos formais e materiais previstos na referida Constituição, a não observância de tais requisitos podem acarretar na declaração de inconstitucionalidade de tais espécies normativas através de um possível controle de constitucionalidade.

O controle de constitucionalidade inicialmente pode ser dividido em um controle preventivo ou repressivo, cabendo principalmente ao poder judiciário executar o segundo tipo de controle citado basicamente através de dois modos, sendo um chamado de controle de constitucionalidade difuso ou também concreto, incidental, de exceção e o outro chamado de controle de constitucionalidade concentrado ou também abstrato, principal, de ação (FERNANDES, 2011).

De acordo com o ordenamento jurídico pátrio, o instituto do amicus curiae é utilizado para possibilitar a participação da sociedade durante os trâmites judiciais, porém, essa forma de manifestação é restrita no que concerne aos processos de controle concentrado de constitucionalidade, uma vez que, a Corte Constitucional (Supremo Tribunal Federal - STF) pautando-se em um juízo de admissibilidade atrelado a requisitos subjetivos (relevância da matéria e representatividade dos postulantes) ${ }^{1}$ pode ou não admitir a participação do amicus curiae.

A existência de possibilidade da participação social perante a atuação do judiciário no procedimento do controle de constitucionalidade já evidencia a importância, ou seja, a premência da comunicação entre o STF e seus jurisdicionados. Considerando o caráter vinculante das decisões $^{2}$ no controle concentrado de constitucionalidade a figura do amicus curiae é meio de 


\title{
REVISTA ELETRÔNICA DA \\ FACULDADE DE DIREITO DE FRANCA \\ www.revista.direitofranca.br \\ v. 6, n.1, dez/2012, ISSN: 1983-4225
}

afirmação do pluralismo social e de participação democrática, conferindo legitimidade aos julgados do Tribunal Constitucional.

O presente artigo busca suscitar o debate questionando sobre a figura do amicus curiae,

\begin{abstract}
${ }^{1}$ Conforme a Lei ${ }^{\circ} 9.868$, de 10.11 .1999 em seu art. $7^{\circ}, \S 2^{\circ}$.
${ }^{2}$ Conforme art. 28, $\S$ único da Lei no 9.868, de 10.11.1999 e art. 10, § $3^{\circ}$ da Lei $n^{\circ} 9.882$, de 03.12.1999.

em sua forma de representação e critérios de admissibilidade adotados argumentativamente nas decisões do Supremo Tribunal Federal se fazer uma oportunidade de participação social ampla e democrática no controle concentrado de constitucionalidade, de modo a permitir contribuição no desenvolvimento das decisões judiciais e a reafirmação dos compromissos da Corte Constitucional Brasileira com a $\mathrm{CF} / 88$ em sua responsabilidade contramajoritária.
\end{abstract}

\section{BREVES CONSIDERAÇÕES SOBRE LEGISLAÇÃO BRASILEIRA E O INSTITUTO DO AMICUS CURIAE}

A participação do amicus curiae no processo de controle concentrado de constitucionalidade é permitida nas ações diretas de inconstitucionalidade (ADI), ações declaratórias de constitucionalidade (ADC) e ações de arguição de descumprimento de preceito fundamental (ADPF), cada qual com suas peculiaridades, definidas principalmente pela Lei $\mathrm{n}^{\circ}$ 9.868/99 ${ }^{3}$ e Lei $n^{\circ} 9.882 / 99^{4}$.

De acordo com a Lei no 9.868/99 não é admitida a intervenção de terceiros nas ações do controle concentrado de constitucionalidade ${ }^{5}$. Apesar disso, a mesma Lei, considerando requisitos como relevância da matéria e a representatividade dos postulantes, possibilitou a manifestação de "órgãos ou entidades"6.

Diante da proibição de intervenção de terceiros pela Lei $n^{\circ}$ 9.868/99 a natureza jurídica do amicus curiae encontra divergências.

Ainda há de se ressaltar que a legislação brasileira criou duas situações jurídicas distintas de intervenção de amicus curiae: uma por iniciativa do julgador outra por iniciativa do próprio órgão ou entidade ${ }^{7}$.

O instituto do amicus curiae no direito brasileiro pode ser visualizado, basicamente, a

\footnotetext{
${ }^{3}$ A Lei $n^{\circ}$ 9.868, de 10.11.1999 dispõe sobre o processo e julgamento da ação direta de inconstitucionalidade e da
} 


\section{REVISTA ELETRÔNICA DA \\ FACULDADE DE DIREITO DE FRANCA \\ www.revista.direitofranca.br \\ v. 6, n.1, dez/2012, ISSN: 1983-4225}

ação declaratória de constitucionalidade perante o Supremo Tribunal Federal.

${ }^{4}$ A Lei ${ }^{\circ}$ 9.882, de 03.12.1999 dispõe sobre o processo e julgamento da arguição de descumprimento de preceito fundamental, nos termos do $\S 1^{\circ}$ do art. 102 da Constituição Federal.

${ }^{5}$ Conforme Lei $n^{\circ}$ 9.868/99: Art. $7^{\circ}$ - Não se admitirá intervenção de terceiros no processo de ação direta de inconstitucionalidade. / Art. 18 - Não se admitirá intervenção de terceiros no processo de ação declaratória de constitucionalidade.

${ }^{6}$ Ainda de acordo com a Lei $n^{\circ}$ 9.868/99: Art. $7^{\circ}$ - [...] $\S 2^{\circ}$ - O relator, considerando a relevância da matéria e a representatividade dos postulantes, poderá, por despacho irrecorrível, admitir, observado o prazo fixado no parágrafo anterior, a manifestação de outros órgãos ou entidades.

${ }^{7}$ A Lei $\mathrm{n}^{\circ} 9.868 / 99 \mathrm{em}$ seu art. $7^{\circ}, \S 2^{\circ}$, estabelece a possibilidade de admissão do amicus curiae ("outros órgãos ou entidades") pelo relator no procedimento da ADI. Já no art. $9^{\circ}, \S 1^{\circ}$ (procedimento da ADI) e art. $20, \S 1^{\circ}$ (procedimento da ADC), ambos com redação idêntica, a referida Lei menciona: “ [...] Em caso de necessidade de esclarecimento de matéria ou circunstância de fato ou de notória insuficiência das informações existentes nos autos, partir de dois ângulos, tomadas as diversas previsões legais que tratam do tema: manifestação por iniciativa do juiz e intervenção voluntária (DEL PRÁ, 2008:127). Nesse diapasão, o amicus curiae também pode ser considerado como um "terceiro de natureza especial". Imprescindível frisar que não há interesse subjetivo das partes na atuação do amicus curiae, esse se caracteriza possivelmente, portanto, como "terceiro" distinto das partes e não como forma de "atuação de terceiros", denominação utilizada pelo direito processual civil.

$\mathrm{Na}$ esteira das breves considerações realizadas sobre o instituto específico em estudo, é possível afirmar que o debate público é elementar ao processo constitucional brasileiro. Destarte, através da figura amicus curiae o STF "literalmente à luz da dicção legal, chama a sociedade para o debate, pois passa a reconhecer que existem outros intérpretes da Constituição que devem participar do jogo de concretização e densificação da Constituição” (FERNANDES, 2011:949).

\section{SOBRE AS DECISÕES QUE ENVOLVEM A PARTICIPAÇÃO DO AMICUS CURIAE E A IMPORTÂNCIA DO INSTITUTO}

Para interagir com o mundo, se expressar, comunicar e viver em sociedade, o homem utiliza a linguagem com diversas finalidades, através de "jogos de linguagem" (WITTGENSTEIN, 1999), que variam de acordo com o contexto em que são empregados.

O giro hermenêutico e linguístico baseia-se na ideia de que a hermenêutica é algo anterior e mais profundo do que a atividade interpretativa, consistindo na análise das várias possibilidades que o ser tem de existir e de se manifestar através de alternativas que se dão no tempo (dimensão histórica). Sendo assim, a compreensão humana é composta de conceitos e préconceitos que são revistos mutuamente. A partir de conclusões propiciadas por Heidegger - sobre 


\section{REVISTA ELETRÔNICA DA \\ FACULDADE DE DIREITO DE FRANCA \\ www.revista.direitofranca.br \\ v. 6, n.1, dez/2012, ISSN: 1983-4225}

o dasein / ser-aí (2002), Gadamer (1997) coloca a dimensão hermenêutica como diálogo e opõe a verdade ao método, procedendo ao giro hermenêutico, indicando a hermenêutica como estudo do fenômeno da compreensão. A operação humana do compreender poderia ser associada a uma

poderá o relator requisitar informações adicionais, designar perito ou comissão de peritos para que emita parecer sobre a questão ou fixar data para, em audiência pública, ouvir depoimentos de pessoas com experiência e autoridade na matéria." Sobre o procedimento da ADPF a Lei $n^{\circ}$ 9.882/99 preconiza em seu art. $6^{\circ}, \S \S 1^{\circ}$ e $2^{\circ}$ : “ $[\ldots] \S 1^{\circ} \underline{S e}$ entender necessário, poderá o relator ouvir as partes nos processos que ensejaram a arguição, requisitar informações adicionais, designar perito ou comissão de peritos para que emita parecer sobre a questão, ou ainda, fixar data para declarações, em audiência pública, de pessoas com experiência e autoridade na matéria. $\S 2^{\circ}$ Poderão ser autorizadas, a critério do relator, sustentação oral e juntada de memoriais, por requerimento dos interessados no processo." Observa-se que o instituto do amicus curiae também pode ser identificado: no Código de Processo Civil em seu art. 482 , $\S \S 1^{\circ}$ a $3^{\circ}$, na Lei $n^{\circ} 10.259 / 01$ em seu art. 14 , $\S 7^{\circ}$ e art. 15 , na Lei ${ }^{\circ} 8.884 / 94$ em seu art. 89, e na Lei $\mathrm{n}^{\circ} 6.385 / 76 \mathrm{em}$ seu art. 31 .

estrutura espiral (não circular) uma vez que o intérprete não finaliza o exercício da compreensão (através do diálogo) do mesmo modo (com os mesmos pré-conceitos) que iniciou.

Em uma perspectiva jurídica, considerando o paradigma do Estado Democrático de Direito após o giro hermenêutico-linguístico, afirma-se que a hermenêutica jurídica, mais precisamente a compreensão - interpretação - aplicação do direito, tem como requisito a linguagem através do discurso, ou seja, do diálogo entre sujeito(s) e objeto(s), além do diálogo entre sujeito(s) e sujeito(s).

Nesse sentido, a interpretação deve concretizar a lei em sua validez, isto é, de acordo com as pretensões que a mesma apresenta (democraticamente), tem de ser compreendida em cada dimensão histórica, ou seja, em cada situação concreta de uma maneira mais adequada ao problema e contexto apresentado. Ressalte-se que para Gadamer (1997:461) compreender é sempre também interpretar e aplicar. Os intérpretes (inseridos em um contexto históricolinguístico diferenciado, com pré-conceitos também diferenciados) dialogam com o texto (e entre si), produzindo e comunicando compreensões (interpretações) diferentes uns dos outros, tal processo ocorre de forma contínua a cada ato de compreenção no decorrer do tempo.

Assim, o processo de interpretação é uma soma aos conhecimentos previamente adquiridos de conhecimentos continuamente construídos, representado em uma espiral hermenêutica, onde existe um enlace dos movimentos da tradição (contexto histórico) do intérprete e da "pré-compreensão" (fusão de horizontes). De tal forma, a compreensão se molda 


\section{REVISTA ELETRÔNICA DA FACULDADE DE DIREITO DE FRANCA \\ www.revista.direitofranca.br \\ v. 6, n.1, dez/2012, ISSN: 1983-4225}

basicamente a partir da consciência histórica do intérprete e do diálogo. O intérprete não simplesmente cede a um objeto que lhe é previamente dado, mas participa na própria constituição do seu sentido, a partir de uma estrutura de mediação, própria da compreensão como um fenômeno histórico, no qual a linguagem mediatiza o passado e o presente (GADAMER, 1997). De tal modo, pode-se dizer que a Constituição $(\mathrm{CR} / 88)$ pode ser interpretada construtivamente (e de modo democrático) por seu(s) intérprete(s) considerada a dimensão histórica, ao mesmo tempo em que, trás em si bases (democráticas) para esta construção.

O momento de concepção da norma não apresenta a mesma realidade social do momento de sua aplicação, sendo assim, devido a esta constante mutação cabe ao intérprete operar o confronto entre momentos históricos (presente e passado) atribuindo interpretações diversas a uma mesma norma em diferentes épocas.

O confronto entre presente e passado se faz complexo, uma vez que a compreensão ulterior possui uma superioridade frente à produção inicial, causando a incapacidade de equiparação entre intérprete e autor original, ao contrário, há uma diferença insuperável entre o intérprete e o autor, diferença que é dada pela distância histórica entre ambos. Sendo assim, cada época entende um texto de uma maneira própria, pois o texto forma (e é formado por) parte do todo da tradição existente.

O verdadeiro sentido de um texto, tal como este se apresenta ao seu intérprete, não depende somente do aspecto ocasional que representam o autor e seu público originário, ou pelo menos, não se resume nisso. Pois esse sentido sempre é determinado também por uma situação histórica do intérprete, e, por consequência, por todo processo objetivo histórico. Portanto, ao ser estabelecido o diálogo, destaca-se que "o sentido de um texto supera seu autor não ocasionalmente, mas sempre. Por isso, a compreensão nunca é um comportamento meramente reprodutivo, mas também é sempre produtivo" (GADAMER, 1997). Estamos obrigados a pôr à prova constantemente todos os nossos 'pré-conceitos', o horizonte do presente não é formado à margem do passado, nem existe um horizonte do presente por si mesmo, assim como não existem horizontes históricos a serem ganhos. Compreender é sempre o processo de fusão desses horizontes.

O diálogo entre os participantes no processo constitucional oportuniza o confronto entre 


\section{REVISTA ELETRÔNICA DA FACULDADE DE DIREITO DE FRANCA \\ $w w w . r e v i s t a$. direitofranca.br \\ v. 6, n.1, dez/2012, ISSN: 1983-4225}

presente e passado não somente sob a perspectiva do julgador, mas também de vários grupos sociais e cidadãos.

Diante da necessidade de fundamentação racional das decisões e pretensões normativas, não podendo o direito ser reduzido à facticidade da coação estatal, mas devendo perseguir a legitimidade produzida pela adesão da comunidade, sob a perspectiva dos princípios e do discurso é possível dizer que $\mathrm{CF} / 88$ trouxe seu texto permeado por abertura semântica normativa, o que permite dinamismo para acompanhar o desenvolvimento da sociedade através da interpretação-aplicação do seu conteúdo e atualização de suas normas. Consoante com a referida Constituição o direito brasileiro tem 'o discurso' realizado através devido processo legal, o que representa a possibilidade de argumentação por seus destinatários, acesso à jurisdição com garantia do contraditório em condições de isonomia.

A partir do momento que um juiz constitucional (poder judiciário), não eleito pelo povo, pode interpretar a Constituição e em nome da tutela de direitos fundamentais insertos nesta Constituição, e invalidar uma lei elaborada pela vontade popular através de um representante eleito democraticamente (poder legislativo), surge um conflito entre a Constituição e a lei, ou seja, entre os direitos fundamentais tutelados constitucionalmente e a 'democracia' (vontade da maioria). Há, portanto, um limite estabelecido pela Constituição para proteções à minoria frente à função legislativa (em seu conteúdo) exercida por representantes eleitos pelo povo.

A intervenção do amicus curiae tem objetivo de pluralizar o debate constitucional, possibilitando que o referido Tribunal venha a dispor de diversos elementos informativos necessários para resolução de controvérsias de forma a minimizar as tensões entre a vontade da maioria e proteção da minoria. É um instituto que valoriza, sob uma perspectiva pluralística, essencialmente democrática, elementos de informação e acervo de experiências transmitidas à Corte Constitucional em um processo, cuja decisão tem implicações políticas, sociais, econômicas, jurídicas e culturais de irrecusável importância.

A participação social no controle de constitucionalidade permite que interpretações dos cidadãos sejam levadas à Corte Constitucional (STF), desde que haja interesse objetivo pela guarda da Constituição. O conteúdo constitucional (e sua interpretação) é reflexo da realidade social, mas também a constrói, a existência do interesse objetivo reforça a importância da 


\section{REVISTA ELETRÔNICA DA \\ FACULDADE DE DIREITO DE FRANCA \\ www.revista.direitofranca.br \\ v. 6, n.1, dez/2012, ISSN: 1983-4225}

fundamentação de uma decisão que poderá atingir a todas as relações e práticas sociais de modo imediato.

A participação social na interpretação constitucional relacionada ao controle de constitucionalidade é de notável importância observados os fundamentos da Constituição Federal de 1988. Assegurar que o debate constitucional seja efetivo de forma ampla (acessível), na seleção dos participantes (dotados de liberdade e igualdade) representa também defesa do Estado Democrático de Direito, em especial do princípio democrático e da perspectiva pluralista, fortalecendo não somente os propósitos do Supremo Tribunal Federal, mas também a própria Constituição da República.

Carole Pateman (1992) compara duas vertentes teóricas: a teoria da democracia participativa clássica (Rousseau e Mill, principalmente) e a teoria contemporânea da democracia, analisado o lugar da participação no conceito de democracia é perceptível preocupação que a democracia seja estendida para além do momento eleitoral, alcançando todas as instituições do Estado, o que confirma o amicus curiae como um ponto positivo para consolidação da democracia brasileira além do âmbito eleitoral.

Nesse sentido, o princípio democrático da $\mathrm{CF} / 88$ não coaduna com uma compreensão estática da democracia, pelo contrário, a democracia é um processo dinâmico inerente a uma sociedade aberta, onde é possível oferecer aos cidadãos liberdade de participação crítica com condições de igualdade. A participação de diferentes grupos em processos judiciais significativos para toda a sociedade cumpre uma função de integração no Estado de Direito, através da manifestação da pluralidade de visões em permanente diálogo, o que contribui para a qualidade da prestação jurisdicional, democratização do processo judicial e garante legitimação dos julgamentos do STF.

Assim, a tarefa de integração da Constituição às práticas sociais não deve ser considerada tarefa exclusiva dos juízes, mas deve-se considerar a participação daqueles que vivenciam a Constituição (principalmente dos grupos diretamente afetados). Esse processo de abertura da hermenêutica constitucional é importante na promoção democrática com informação dos julgadores para que haja, se necessário, adequação da decisão a ser proferida. O diálogo com a sociedade auxilia e permite ao magistrado considerar observações trazidas pelos participantes, 


\section{REVISTA ELETRÔNICA DA FACULDADE DE DIREITO DE FRANCA \\ www.revista.direitofranca.br \\ v. 6, n.1, dez/2012, ISSN: 1983-4225}

para que ele então fundamente os posicionamentos que adota na construção da decisão judicial, solucionando o caso concreto de forma que melhor irá condizer com a história institucional e progresso social.

Häberle (2001) é um autor de relevância devido sua tese baseada em "uma sociedade aberta de intérpretes da Constituição", que propõe a ampliação do círculo de intérpretes constitucionais com pluralismo e abertura característicos das sociedades democráticas. Nesse deslinde, de acordo com o referido autor a interpretação constitucional deve ser realizada de forma aberta, coadunando com uma sociedade igualmente aberta, devendo haver critérios de interpretação constitucional, sendo tais critérios mais abertos quanto mais pluralista for a sociedade em questão. Pois, todo aquele que vive o contexto regulado por uma norma seria indireta ou, até mesmo diretamente, um intérprete dessa norma. $\mathrm{O}$ destinatário da norma poderia assim, ser considerado participante ativo, muito mais ativo do que se pode supor tradicionalmente, do processo hermenêutico. Como os julgadores não são apenas os intérpretes jurídicos da Constituição que vivem a norma, não devem deter-se a eles o monopólio da interpretação da Constituição.

No sentido elucidado, cuida-se de Constituição enquanto processo público. Diante de uma possível objeção de que "a unidade da Constituição" poderia se perder com a adoção desse entendimento, deve-se observar que as regras básicas para interpretação remetem a um senso que resulta da conjugação desses diferentes intérpretes da Constituição no exercício de suas funções. A própria abertura da Constituição demonstra que não apenas o constitucionalista (julgador) participa desse processo de interpretação. A unidade da Constituição surge da conjugação do processo e das funções de diferentes intérpretes (HABERLE, 1997).

Habermas (2003) em sua teoria do "agir comunicativo" considera que como forma de atestar a legitimidade das decisões, a construção das mesmas deve se dar por meio do diálogo efetivo, com a participação de todos os seus destinatários, uma vez que, todos os afetados pelas normas jurídicas poderiam, em princípio, ser considerados coautores das normas aplicadas.

Sob este prisma, em sede de controle de constitucionalidade, a legitimidade de uma Corte Constitucional decorreria da aceitação da decisão final pelos participantes do discurso, sendo a atuação da Corte Constitucional avaliada e fiscalizada pelos cidadãos quando 


\section{REVISTA ELETRÔNICA DA FACULDADE DE DIREITO DE FRANCA \\ www.revista.direitofranca.br \\ v. 6, n.1, dez/2012, ISSN: 1983-4225}

efetivamente se exerce uma jurisdição aberta à participação de todos os interessados no processo de construção das decisões constitucionais.

De todo modo, apesar dos progressos jurídicos, das incontestáveis contribuições para legitimidade de decisões e melhoria na qualidade da prestação jurisdicional desenvolvidas e possíveis a partir das teorias aqui pontuadas (dos autores Häberle e Habermas), acredita-se que as mesmas sejam insuficientes para o trabalho sob a perspectiva para desenvolvimento do(s) meio(s) de democratização ora existentes no controle de constitucionalidade do Brasil (amicus curiae junto ao STF) diante dos desafios e necessidades encontrados no sistema brasileiro. Há também de se colocar como relevante a dificuldade de representação de forma equitativa das diversas e complexas camadas / estruturas sociais brasileiras diante do judiciário. Salutar sugerir que, é imprescindível o desenvolvimento das teorias citadas e de outras teorias por pesquisas científicas para inovações e aperfeiçoamentos da participação social no controle concentrado de constitucionalidade.

Não se pode negar que, conforme observa Habermas (2003), o juiz deve realizar uma reconstrução racional do ordenamento jurídico à luz das práticas sociais, a exemplo da interpretação construtiva de Dworkin (1999), que permite dar uma coerência ao ordenamento jurídico de tal modo que seja possível que as decisões judiciais possam ser corretas.

Considerando a figura do amicus curiae adotada pelo STF, verifica-se que a efetiva participação social é condicionada à uma decisão (preliminar ao mérito da ação de controle concentrado).

Assim, cabe ao juiz inevitável papel decisório tanto no (in)-deferimento de pedidos para participação de amicus curiae em processos de controle constitucional utilizando de critérios altamente interpretativos para sua fundamentação, quanto, ao proferir decisão final do caso concreto, sendo pertinente mencionar a teoria do "direito como integridade" desenvolvida por Ronald Dworkin (1999).

Dworkin desenvolve sua teoria através de metáforas como a do 'romance em cadeia', onde o juiz ('juiz Hércules') assume o papel de romancista e postura de participante, argumentando com o restante da sociedade, é possível que este juiz venha a proferir decisão que preencha um momento histórico institucional com a melhor leitura que a sociedade faz de suas 


\section{REVISTA ELETRÔNICA DA FACULDADE DE DIREITO DE FRANCA \\ www.revista.direitofranca.br \\ v. 6, n.1, dez/2012, ISSN: 1983-4225}

práticas sociais e da 'comunidade de princípios', ambas compartilhadas. Ou seja, à luz de um direito dotado de integridade é possível que o juiz chegue à resposta correta, considerando que, "a atividade decisória dos juízes não se produzem no vácuo, mas sim em constante diálogo com a história" (FERNANDES; PEDRON, 2008: 213-223).

Tanto nas decisões de mérito dos casos concretos (finais), quanto em relação às decisões (preliminares) sobre à permissão da participação de amicus curiae perante o STF (decisão esta pautada em critérios subjetivos estabelecidos por lei específica) é preciso que o julgador adote uma postura de responsabilidade e considere a compreensão do direito à partir de uma teoria que o busque à luz de um conjunto coerente de princípios, integrado à história institucional da sociedade para melhor interpretação tanto das normas e das práticas, quanto do caso concreto.

A partir de tal postura, será possível alcance da melhor solução, ou seja, da resposta correta. Inicialmente pode referir-se a uma resposta quanto à decisão do pedido para participação como amicus curiae em determinado processo - sendo que, esta quando corretamente proferida, permitirá ao juiz proferir a decisão final (do controle de constitucionalidade concentrado) também de forma correta, ou seja, com coerência.

Ao julgar o (in)-deferimento do pedido de participação como amicus curiae, o juiz deve levar em consideração cada pedido em questão, analisando, assim, caso a caso: a importância da participação a ser deferida como representação de um instituto democrático (amicus curiae) para legitimidade da decisão de mérito a ser proferida no controle de constitucionalidade concentrado, e também a(s) possível(is) contribuição(ões) a ser(em) prestada(s) para o processo em análise, e de forma geral, para o Estado Democrático de Direito e para a própria concepção de democracia construída no país.

Ao decidir, o magistrado voltar-se-á para o restante da comunidade, levando a sério que ela pode assumir uma importante participação nos processos constitucionais para análise do objeto de controle concentrado, de modo a auxiliar o julgador na atividade interpretativa. Ressalte-se que o magistrado, por sua vez, mesmo atento às participações argumentativas da sociedade e às apresentações de tentativas na reconstrução das práticas sociais com interligação destas ao direito à sua melhor luz, argumenta em posição independente das pressões majoritárias ou reivindicações minoritárias 'bem intencionadas' e informações meramente especulativas que 


\section{REVISTA ELETRÔNICA DA FACULDADE DE DIREITO DE FRANCA \\ www.revista.direitofranca.br \\ v. 6, n.1, dez/2012, ISSN: 1983-4225}

possam ter sido trazidas à corte. O juiz aprecia o que lhe é oferecido como contribuição pelo amicus curiae, porém busca aliar a compreenção do conteúdo dessa colaboração externa e fundamentação das decisões que profere à "argumentos de princípio", que guardam coerência com a história institucional [esta é continuamente (re)construída pelo diálogo, práticas e escolhas (que implicam acertos ou erros) no cotidiano dos participantes da sociedade], dotando o direito de integridade conforme leciona Dworkin.

Apesar do interesse objetivo na manifestação do amicus curiae e mesmo havendo esforços para alcance de um debate amplo, democrático, mais completo e diverso possível, é preciso considerar que poderão haver limites e percalços nas tentativas de obtenção desse patamar, podem surgir durante a manifestação do amicus curiae apresentações de informações incompletas ou assimétricas à Corte. O julgador, por sua vez, consciente em fundamentar a decisão nos "argumentos de princípio" se abstém de decisões com argumentações meramente tendenciosas (embasadas em afirmações de declarações parciais, incompletas, casuístas) e evita possíveis distorções no uso de informações assimétricas que possam ser apresentadas por participantes na qualidade de amicus curiae em diálogo junto à Corte.

Considerando a dimensão pragmática da linguagem jurídica, a negativa da pretensão participativa do amicus curiae por falta de "relevância da matéria" ou/e "representatividade dos postulantes", afirma-se que, por meio somente da legislação (em sua literalidade) não é possível a priori identificar as causas que supostamente interessariam somente a parcelas da sociedade (FERNANDES, 2011:795), sendo que, apenas no interior do discurso de aplicação se poderia reconstruir uma norma dotando-a de sentido (GÜNTHER, 1993). De tal modo, somente a cada argumento de decisão seria possível realização de análise com integridade dos critérios estabelecidos pela legislação (relevância da matéria e representatividade dos postulantes) interpretando e dotando-os de contextualização com particular exigência do caso concreto a ser julgado, além da consideração da participação pleiteada para a sociedade, para o Estado Democrático de Direito e para legitimidade da futura decisão.

\section{CASO DO AGRAVO REgIMENTAL NA ADI 3396 E A (IM)POSSIBILIDADE RECURSAL}




\section{REVISTA ELETRÔNICA DA FACULDADE DE DIREITO DE FRANCA \\ www.revista.direitofranca.br \\ v. 6, n.1, dez/2012, ISSN: 1983-4225}

Foi ajuizada ADI 3396 pelo Conselho Federal da Ordem dos Advogados do Brasil (OAB) questionando o artigo $4^{\mathrm{a}}$ da Lei Federal 9.527/97, que dispõe sobre a relação empregatícia dos advogados atuantes em órgãos públicos e sociedades de economia mista frente ao tratamento diferenciado do estabelecido pela Lei 8.906/94 (Estatuto da Advocacia).

Ocorre que, na referida ADI o ministro Celso de Mello negou o pedido de um procurador da Fazenda Nacional para participação como amicus curiae que recorreu da decisão através de agravo regimental.

No julgamento do agravo regimental o ministro Celso de Mello (posteriormente acompanhado de Cezar Peluso, Gilmar Mendes e Ricardo Lewandowski) reconheceu o referido agravo de acordo com a jurisprudência do STF (até então de forma interpretativa, o entendimento jurisprudencial é que não cabe recurso da decisão que admite a participação do amicus curiae, mas permite o cabimento de recurso para decisão que a denega - ADI 3105). Foi alegado que: "O relator pode se equivocar e o Plenário, entender que determinada entidade tem representatividade para participar do julgamento como amigo da Corte" 9 .

Apesar de ter reconhecido o cabimento do recurso entendendo pela interpretação e extensão da lei de acordo com jurisprudência - ADI 3105, Celso de Mello votou pelo desprovimento do mesmo, mantendo a fundamentação dada em sua decisão de indeferimento, no sentido que o procurador que requereu a participação (recorrente) não teria representatividade adequada para ser admitido como amicus curiae no julgamento por ser pessoa física (observância pela literalidade da lei - artigo $7^{\circ}$ da Lei $n^{\circ}$ 9.889/99 - palavras: "órgãos ou entidades").

Ocorre que, antes do debate sobre o mérito da questão, outro fator levantou divergência: $a$ possibilidade de modificação sobre entendimento jurisprudencial quanto ao cabimento de

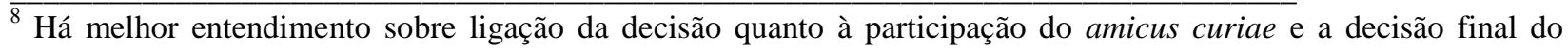
controle de constitucionalidade concentrado no desenvolvimento no tópico '4' do presente artigo.

${ }^{9}$ Informativo no 665 do STF - Min. Celso de Mello - decisão em: ADI 3396AgR/DF.

recurso da decisão que nega a participação do amicus curiae foi o que gerou embate de interpretações à priori.
} 


\section{REVISTA ELETRÔNICA DA FACULDADE DE DIREITO DE FRANCA \\ www.revista.direitofranca.br \\ v. 6, n.1, dez/2012, ISSN: 1983-4225}

Após as considerações do relator Celso de Mello, o ministro Marco Aurélio (posteriormente acompanhado de Ayres Britto, Dias Toffoli, Luiz Fux e Rosa Weber) divergiu de Celso de Mello, defendendo o não cabimento do recurso de agravo regimental por considerar que a decisão do relator nesse caso é "irrecorrível" (observância pela literalidade da lei interpretação do art. $7^{\circ}, \S 2^{\circ}$ da Lei no $9.868 / 99$ para o não-cabimento de recursos interpostos por terceiros estranhos à relação processual nos processos objetivos de controle de constitucionalidade em nenhuma hipótese. Verifica-se assim que, Marco Aurélio é contrário à exceção aberta pela jurisprudência quanto ao reconhecimento do recurso por terceiros apenas para impugnar decisão de não-admissibilidade de sua intervenção nos autos).

O resultado da votação do agravo regimental, portanto, estava em 5 (alteração) a 4 (manutenção) por seu não conhecimento. Por considerar que a decisão a ser tomada pode mudar uma jurisprudência do STF, diante da ausência de Joaquim Barbosa e Carmem Lucia, o Plenário decidiu aguardar a posição de ministros ausentes nesse julgamento para definição de um resultado final, pediu-se a suspensão do processo, que foi deferida.

Com a decisão a ser proferida sobre a questão incidental (mas que se tornou essencial) do agravo regimental da ADI 3396, há risco de incoerência com a postura tomada na ADI 2777 que autorizou a sustentação oral por parte do amicus curiae, ampliando sua participação, o STF abre possibilidade de reconstruir seu entendimento jurisprudencial quanto à matéria, escrevendo mais uma página em sua história institucional.

\section{CONCLUSÃO}

Por fim, para resguardar o equilíbrio entre os poderes (executivo, legislativo e judiciário) no desempenho de suas funções, proporcionar melhor prestação jurisdicional (principalmente nas ações de controle concentrado) com equilíbrio entre as tensões advindas da decisão judicial e alcance da decisão correta (não restritivas ou aditivas) à luz do 'direito como integridade', se faz considerável a realização de debates amplos e abertos que possibilitem atenção às admissíveis e relevantes contribuições do instituto do amicus curiae para decisões judiciais legitimadas democraticamente. O (in)-deferimento das pretensões de participação como amicus curiae, 


\section{REVISTA ELETRÔNICA DA \\ FACULDADE DE DIREITO DE FRANCA \\ www.revista.direitofranca.br \\ v. 6, n.1, dez/2012, ISSN: 1983-4225}

devem se fazer caso a caso, observada a importância da efetividade do instituto para cada caso. Interligar o exercício do controle de constitucionalidade judicial às balizas democráticas reveste-o de legitimidade, tornando indispensável disponibilização e o aperfeiçoamento de instrumentos processuais para participação social no processo decisório.

\section{REFERÊNCIAS BIBLIOGRÁFICAS}

BRASIL. Constituição da República Federativa do Brasil. 17. ed. São Paulo: Revista dos Tribunais, 2012.

BRASIL. Lei n. 9.868, de 10 de Novembro de 1999. Dispõe sobre o processo e julgamento da ação direta de inconstitucionalidade e da ação declaratória de constitucionalidade perante $o$ Supremo Tribunal Federal. Disponível em: 〈http://www.planalto.gov.br/CCIVIL/Leis/L9868.htm>. Acesso em: 17 dez. 2012.

BRASIL. Lei n. 9.882, de 03 de Dezembro de 1999. Dispõe sobre o processo e julgamento da arguição de descumprimento de preceito fundamental, nos termos do $§ 1$ lo do art. 102 da Constituição Federal. Disponível em: 〈http://www.planalto.gov.br/ccivil_03/Leis/L9882.htm〉. Acesso em: $17 \mathrm{dez} .2012$.

BUENO FILHO, Edgard Silveira. Amicus curiae - a democratização do debate nos processos de controle de constitucionalidade. Brasília: Revista CEJ. n. 19, 2002.

DEL PRÁ, Carlos Gustavo Rodrigues. Amicus curiae: instrumento de participação democrática e de aperfeiçoamento da prestação jurisdicional. Curitiba: Juruá, 2008.

DWORKIN, Ronald. O império do direito. São Paulo: Martins Fontes, 1999.

DWORKIN, Ronald. Uma questão de princípios. 2. ed. São Paulo: Martins Fontes, 2001.

DWORKIN, Ronald. Levando os direitos a sério. São Paulo: Martins Fontes, 2002.

DWORKIN, Ronald. A justiça de toga. São Paulo: Martins Fontes, 2010.

ELY, John Hart. Democracia e desconfiança: uma teoria do controle judicial de constitucionalidade. São Paulo: Martins Fontes, 2010.

FERNANDES, Bernardo Gonçalves; PEDRON, Flávio Quinaud. Poder judiciário e $(m)$ crise. Rio de Janeiro: Lumen Juris, 2008.

FERNANDES, Bernardo Gonçalves. Curso de direito constitucional. 3. ed. Rio de Janeiro: Lumen Juris, 2011.

GADAMER, Hans-Georg. Verdade e método: traços fundamentais de uma hermenêutica filosófica. 3. ed. Petrópolis: Vozes, 1997.

GADAMER, Hans-Georg. O problema da consciência histórica. 2. ed. Rio de Janeiro: FGV, 2003. 


\section{REVISTA ELETRÔNICA DA \\ FACULDADE DE DIREITO DE FRANCA \\ www.revista.direitofranca.br \\ v. 6, n.1, dez/2012, ISSN: 1983-4225}

GÜNTHER, Klaus. The sense of appropriateness: application discourses in morality and law. New York: State University of New York, 1993.

HABERMAS, Jürgen. Direito e democracia: entre facticidade e validade. 2. ed. Rio de Janeiro: Tempo Brasileiro, 2003.

HÄBERLE, Peter. Hermenêutica constitucional - sociedade aberta dos intérpretes da constituição: contribuição para a interpretação pluralista e procedimental da constituição. Porto Alegre: Sergio Antônio Fabris, 1997.

HÄBERLE, Peter. El estado constitucional. Cidad do México: UNAM, 2001.

HEIDEGGER, Martin. Ser e Tempo. 11. ed. Petrópolis: Vozes, 2002.

MAUS, Ingeborg. O judiciário como superego da sociedade. Rio de Janeiro: Lumen Juris, 2010.

MORRISSON, Wayne. Filosofia do direito: dos gregos ao pós-modernismo. São Paulo: Martins Fontes, 2006.

OLIVEIRA, Marcelo Andrade Cattoni de (coord.). Jurisdição e hermenêutica constitucional no estado democrático de direito. Belo Horizonte: Mandamentos, 2004.

PATEMAN, Carole. Participação e teoria democrática. São Paulo: Paz e Terra, 1992.

SOUZA NETO, Cláudio Pereira. Jurisdição constitucional, democracia e racionalidade prática. Rio de Janeiro: Renovar, 2001.

STRECK, Lenio Luiz; BARRETTO, Vicente de Paulo; TOMAZ DE OLIVEIRA, Rafael. Ulisses e o canto das sereias: sobre ativismos judiciais e os perigos da instauração de um terceiro turno da constituinte. Revista de Estudos Constitucionais, Hermenêutica e Teoria do Direito (RECHTD), n. 2, v. 1, São Leopoldo: Unisinos, 2009.

STRECK, Lenio Luiz. Verdade e consenso. 3. ed. Rio de Janeiro: Lumen Juris, 2009.

WITTGENSTEIN, Ludwig. Investigações filosóficas. São Paulo: Nova Cultural, 1999.

Decisões/ Acórdãos

BRASIL. Supremo Tribunal Federal. Informativo $n^{o}$ 665. Disponível em: 〈http://www.stf.jus.br/arquivo/informativo/documento/informativo665.htm>.

Acesso em: 20 out. 2012

BRASIL. Supremo Tribunal Federal. Ação Direta de Inconstitucionalidade $n^{o}$. 3396. Rel. Ministro Celso de Mello. Brasília, DF, 23 de fevereiro de 2011. Disponível em: 〈www.stf.jus.br/portal/processo/verProcessoTexto.asp?id=2760446\&tipoApp=RTF>. Acesso em: 10 nov. 2012

BRASIL. Supremo Tribunal Federal. Ação Direta de Inconstitucionalidade $n^{o}$. 3396AgR/DF. Rel. Ministro Celso de Mello. Brasília, DF, 10 de maio de 2012. 


\section{REVISTA ELETRÔNICA DA \\ FACULDADE DE DIREITO DE FRANCA \\ www.revista.direitofranca.br \\ v. 6, n.1, dez/2012, ISSN: 1983-4225}

BRASIL. Supremo Tribunal Federal. Ação Direta de Inconstitucionalidade $n^{o}$. 3105. Rel. Ministra Ellen Gracie. Brasília, DF, 18 de agosto de 2004.

BRASIL. Supremo Tribunal Federal. Ação Direta de Inconstitucionalidade $n^{o}$. 2777. Rel. Ministro Cezar Peluso. Brasília, DF, 16 de outubro de 2003. 